\title{
In Silico Designing of Novel Thiazolidine-2-one Derivatives as Dual PDE4/7 Inhibitors for Inflammatory Disorders
}

\author{
AJMER SINGH GREWAL ${ }^{1 *}$, NEELAM SHARMA ${ }^{1}$, SUKHBIR SINGH $^{1}$ AND \\ SANDEEP ARORA ${ }^{1}$ \\ ${ }^{1}$ Chitkara College of Pharmacy, Chitkara University, Rajpura, Punjab, India \\ *Email: ajmergrewal2007@gmail.com
}

Received: June 02, 2017 I Revised: July 05, 2017 I Accepted: Sept. 07, 2017

Published online: Nov. 02, 2017

The Author(s) 2017. This article is published with open access at www.chitkara.edu.in/publications

\begin{abstract}
Phosphodiesterase 4 (PDE4) and phosphodiesterase 7 (PDE7), members of PDE super family, catalyse metabolism of secondary messenger cyclic adenosine monophosphate leading to augmented inflammatory processes in pro-inflammatory and immune-modulatory cells. Dual inhibitors of PDE4/7 are a novel class of drug candidates which can regulate pro-inflammatory as well as function of immune T-cell and are particularly beneficial for the treatment of various inflammatory diseases devoid of unwanted actions. Intense efforts have been directed towards the development of effective dual inhibitors of both PDE4 and PDE7, but not much success has been reported till yet. The aim of present study was to design some newer substituted thiazolidine-2-one derivatives as dual inhibitors of PDE4/7 using structure based rational drug design approach.A new series of thiazolidine-2-one analogues were designed and molecular docking was performed using AutoDock Vina to explore the bonding interactions of the designed molecules with the amino acid residues in the active site of target proteins. The docking study indicated that all the substituted thiazolidine-2-one derivatives have appreciable binding interactions with protein residues of both PDE4 and PDE7. The newly designed compounds could be used as lead molecules for development potent and non-toxic dual inhibitors of PDE4/7 for the management of various inflammatory conditions.
\end{abstract}

Keywords: Anti-inflammatory activity; Docking; Drug design; Dual PDE4/7 inhibitors; Thiazolidine-2-one derivatives.
Journal of Pharmaceutical Technology, Research and Management Vol-5, No-2, November 2017 pp. 149-162 
Grewal, A.S.

Sharma, N.

Singh, $\mathrm{S}$.

Arora, S.

\section{INTRODUCTION}

Phosphodiesterase 4 (PDE4) and phosphodiesterase 7 (PDE7) belong to the cyclic nucleotide PDE super family and catalyse the metabolism of cyclic adenosine monophosphate (cAMP) to its inactive metabolite AMP (Conti et al., 2003). Intracellular secondary messenger, cAMP regulates many biological responses in humans like inflammation, lipid metabolism and apoptosis. cAMP is believed to help in maintaining homeostasis of immune system by promoting secretion of anti-inflammatory intermediates as well as suppressing the secretion of pro-inflammatory intermediates by the cells of immune system. A wide range of anti-inflammatory effects such as decreased proliferative response, decreased pro-inflammatory cytokine production, and decreased surface marker expression in leukocytes can be achieved through elevation of intracellular cAMP levels (Souness et al., 2000; Castro et al., 2005; Baumer et al., 2007). PDE4 enzyme is mainly expressed in every pro-inflammatory and immunomodulatory cell (Giembycz, 2002; Tasken \& Aandahl, 2004). The inhibition of PDE4 results in increased levels of intracellular cAMP in inflammatory cells which activate some particular protein kinase cascade leading to a wide range of anti-inflammatory responses(Caron \& Vazquez, 2001; Burnouf \& Pruniaux, 2002; Sanz et al., 2005; Press \& Banner, 2009; Felding et al., 2014). Amongst the wide variety of small molecule PDE4 inhibitors, rolipram, cilomilast, roflumilast and apremilast are some of the most characterized PDE4 inhibitors to date (Kodimuthali et al., 2008; Man et al., 2009; Beghè et al., 2013). Roflumilast and apremilast were permitted by the Food and Drug Administration as oral drugs for management of chronic obstructive pulmonary disease and psoriatic arthritis in 2011 and 2014, respectively (Guariento et al., 2017; Grewal et al., 2017). PDE7 inhibition leads to increased levels of cAMP resulting in decrease in oedema, cellular inflammation, mucous secretion and bronchoconstriction. Efficacy of the inhibitors of PDE7 enzyme has been reported recently in animal models as anti-inflammatory agents and represents a new class of drugs the management of various inflammatory disorders (Gil et al., 2008; Redondo et al., 2012; Grewal et al., 2017a). BRL50481 (3-(N,N-dimethylsulfonamido)-4-methylnitrobenzene) is the only officially available selective inhibitor of PDE7 which was discovered in 2004 (Smith et al., 2004; Christensen et al., 2012).

Dual PDE4/7 inhibitors could be valuable for the treatment of a variety of immune and inflammatory disorders devoid of unwanted adverse effects. The dual inhibitors of PDE4/7 inhibit the T-cell component of a disorder, at least to some extent due to inhibition of PDE7 enzyme, and possess antiinflammatory activity, elicited due to inhibition of PDE4 enzyme. In addition, dual inhibitors of PDE4/7 could produce more potent activity than the selective 
PDE4 or PDE7 inhibitor for management of a large range of immunity and inflammatory disorders due to a synergetic action with lesser unwanted actions. This concept of synergetic effect is supported by the coincidental expression of PDE4 and PDE7 subtypes in various immunity and inflammatory cells (Castro et al., 2005; Lakics et al., 2010; Vávrová, 2016; Levy et al., 2016). Various dual inhibitors of PDE4/7 developed include pyrazolo[3,4-b]pyridine derivatives, purine derivatives, pyrimidine derivatives, quinazoline derivatives, isochromenones and isoxazolinespirocyclicscaffold based compounds which had demonstrated their efficacy in a series of in vitroassays as well as animal models and suggest the potential of these compounds for the management of a large range of inflammatory diseases (Hatzelmann et al., 2002; Gil et al., 2008a; Pelcman et al., 2010; Pitts et al., 2002; Rudra et al., 2012; Rudra et al., 2013; Jankowska et al., 2017).

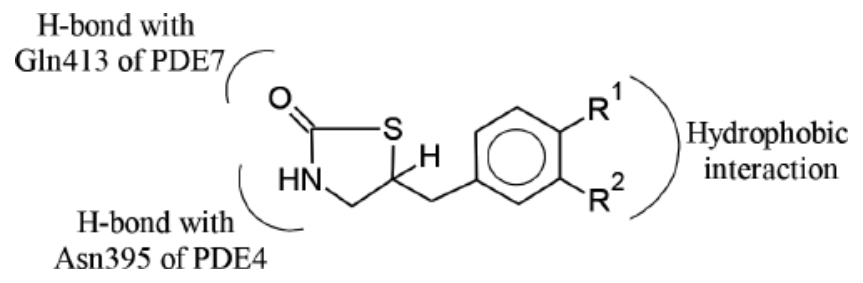

Figure 1: Pharmacophoric features required for dual PDE4/7 inhibitory activity and general structure of novel thiazolidine-2-one derivatives designed as potential dual PDE4/7 inhibitors.

Development of dual inhibitors of PDE4/7 will yield novel class of therapeutic drugs useful for the management of wide range of inflammatory and immune diseases with auniquemode of action. The pharmacophoric features required for dual PDE4 and PDE7 inhibitory activity were identified based on information from available X-ray crystallographic structures of PDE4inhibitors complexes and PDE7-inhibitors complexes from the PDB database. In the structure of ligands, $\mathrm{H}$-bond donor is essential for $\mathrm{H}$-bond interaction with Asn395 residues of PDE4 protein and H-bond acceptor is essential for H-bond interaction with Gln413 residue of PDE7 protein. Aromatic ring is also required attached to the main ring for hydrophobic interactions with the amino acid residues of PDE4 and PDE7 proteins. Several five membered heterocyclic derivatives were developed as PDE4 and PDE7 inhibitors such as pyrrolidine derivatives, thiazole derivatives, thiadiazoles, isoxazoles, and furan derivatives (Nichols et al., 2006; Vergne et al., 2004; Vergne et al., 2004a; Rudra et al., 2013; Jankowska et al., 2017). Considering the concept of bioisosterism (replacing carbon atom with that of sulphur atom) and the pharmacophoric features required for dual PDE4/7 inhibition as well as
In Silico Designing

of Novel

Thiazolidine-2-one

Derivatives as Dual

PDE4/7 Inhibitors

for Inflammatory

Disorders

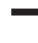


Grewal, A.S. Sharma, N. Singh, S. Arora, S. recognizing the potential role of heterocyclic compounds in wide therapeutic areas including inflammation we have designed some novel thiazolidine-2one derivatives (Figure 1) asdual PDE4/7 inhibitors using molecular docking studies of designed molecules.

\section{EXPERIMENTAL}

Molecular docking was performed for the designed molecules in the binding site of both PDE4 and PDE7 proteins using AutoDock Vina (Trott \& Olson, 2010) and the graphical user interface, AutoDock Tools (Morris et al., 2009).The 2-D chemical structures of the ligands were prepared by Marvin Sketch (Marvin 15.9.21, 2015, ChemAxon) and converted to 3-D by Frog2 server based on a graph decomposition of the compounds coupled with an identification of the stereo-centres for which the chirality is unspecified (Miteva et al., 2010). The ligands were converted to PDBQT files from MOL format using AutoDock Tools. After assessing a numbers of co-crystallized structures of PDE4 and PDE7 available in the protein data bank (http://www.rcsb.org/pdb), the best ligand bound complexes (PDB entry: 3HMV and 4PM0 for PDE4 and PDE7, respectively) were selected with complexes having maximum resolution and best binding interactions between ligands and proteins. The PDB files of the target proteins were edited using PyMOL (The PyMOL Molecular Graphics System, Version 1.7.4.5 Edu, Schrödinger, LLC.) by removing complexed inhibitor, all the water molecules as well as all non-interacting ions. The PDBQT files of target proteins were generated from the PDB files using AutoDock Tools and all the polar hydrogen atoms were added to the protein molecule. The "Grid" of AutoDock Tools was used for calculating the grid parameters and all the data regarding target protein, ligand, grid size and geometry were saved in TXT file. The reference ligands were docked in the active site of target proteins and compared with that of the co-crystallized inhibitors for determining the accuracy of the docking protocol. The prepared ligand molecules were docked in the active site of the refined PDE4 and PDE7 models utilizing AutoDock Vina and scored by using scoring function. The binding free energy $(\Delta G)$ for each ligand was reported in log file. PyMOL was utilized for the analysis of the binding interactions (including H-bond and hydrophobic interactions) of the ligands in the active site of target proteins.

\section{RESULTS AND DISCUSSION}

In silico studies were performed to explore the affinity and binding interactions of the designed compounds in the active site of both PDE4 and PDE7 proteins (PDB entry: 3HMV and 4PM0 for PDE4 and PDE7, respectively). The 
reference ligands were docked into the active site of PDE4 and PDE7; and the docked reference inhibitors of PDE4 and PDE7 produced a similar binding pattern and superposition on the binding mode of co-crystallized inhibitors validating accuracy of docking methodology. All the designed thiazolidine-2one analogues were docked in the active site of PDE4 and PDE7 proteins; and most of the designed molecules displayed considerable binding interactions in the active site of both PDE4 and PDE7 proteins and stability of the ligandprotein complex was determined by analysing binding free energy $(\Delta \mathrm{G}, \mathrm{kcal} /$ mol) of the best docked poses (Table 1).
In Silico Designing of Novel

Thiazolidine-2-one Derivatives as Dual PDE4/7 Inhibitors for Inflammatory Disorders

Table 1: Molecular propertiesand docking score of best-docked poses of designed thiazolidine-2-one derivatives (1-18).

\begin{tabular}{|c|c|c|c|c|c|c|c|c|}
\hline Comp. & Structure & $\begin{array}{c}\text { Mol. } \\
\text { Formula }\end{array}$ & $\begin{array}{l}\text { Mol. } \\
\text { Wt." }\end{array}$ & $\underset{\mathbf{P}^{\#}}{\mathbf{L o g}}$ & $\mathbf{H B A}^{\#}$ & HBD $^{\#}$ & $\begin{array}{c}\Delta \mathbf{G} \\
\text { for } \\
\text { PDE4 }\end{array}$ & $\begin{array}{c}\Delta \mathbf{G} \\
\text { for } \\
\text { PDE7 }\end{array}$ \\
\hline 1 & & $\mathrm{C}_{10} \mathrm{H}_{11} \mathrm{NOS}$ & 193.26 & 2.14 & 1 & 1 & -7.1 & -6.3 \\
\hline 2 & & $\mathrm{C}_{10} \mathrm{H}_{11} \mathrm{NO}_{2} \mathrm{~S}$ & 209.26 & 1.85 & 2 & 2 & -7.2 & -6.7 \\
\hline 3 & & $\mathrm{C}_{10} \mathrm{H}_{11} \mathrm{NO}_{2} \mathrm{~S}$ & 209.26 & 1.85 & 2 & 2 & -7.3 & -7.8 \\
\hline 4 & & $\mathrm{C}_{10} \mathrm{H}_{11} \mathrm{NO}_{3} \mathrm{~S}$ & 225.26 & 1.57 & 3 & 3 & -7.5 & -7.0 \\
\hline 5 & & $\mathrm{C}_{11} \mathrm{H}_{13} \mathrm{NO}_{3} \mathrm{~S}$ & 239.29 & 1.60 & 3 & 2 & -7.9 & -7.5 \\
\hline 6 & & $\mathrm{C}_{11} \mathrm{H}_{13} \mathrm{NO}_{3} \mathrm{~S}$ & 239.29 & 1.60 & 3 & 2 & -7.8 & -7.1 \\
\hline 7 & & $\mathrm{C}_{12} \mathrm{H}_{15} \mathrm{NO}_{3} \mathrm{~S}$ & 253.32 & 1.63 & 3 & 1 & -7.6 & -7.0 \\
\hline 8 & & $\mathrm{C}_{13} \mathrm{H}_{15} \mathrm{NO}_{3} \mathrm{~S}$ & 253.32 & 1.94 & 3 & 2 & -7.8 & -7.3 \\
\hline 9 & & $\mathrm{C}_{13} \mathrm{H}_{15} \mathrm{NO}_{3} \mathrm{~S}$ & 253.32 & 1.94 & 3 & 2 & -7.6 & -7.5 \\
\hline
\end{tabular}


Grewal, A.S.

Sharma, N.

Singh, $\mathrm{S}$.

Arora, S.

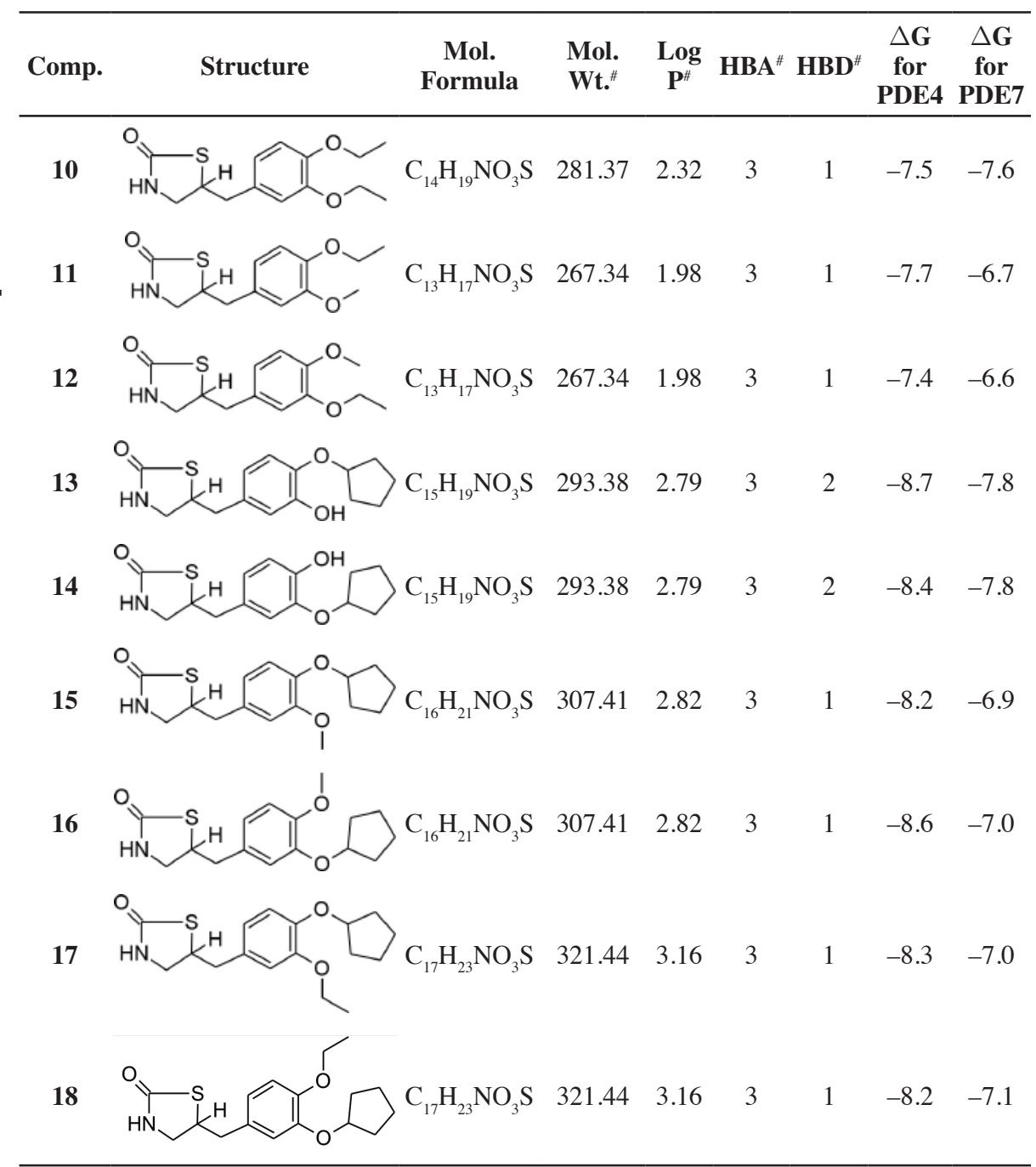

${ }^{\#}$ Log P, HBA, HBD, and Mol. Wt., were calculated by Marvin tools of Marvin Sketch v5.5.

Based on the lowest docking free energy and better binding interactions in the active site of PDE4 protein, compounds 3, 7, 10, 11, 13 and 18 were further analysed in details by PyMOL. The binding poses showing bonding interactions (Hydrogen bonds) and overlays of the selected molecules with that of the PDB ligand of 3HMV in the active site of PDE4 protein are presented in figures 2 and 3. The docked pose of the selected compounds 3, 7, 10, 11, 13 and 18 showed $\mathrm{H}$-bonding interaction between -NH of thiazolidine-2-one ring of the selected compounds and carbonyl group at Asn395 residue of the PDE4 protein with bond length of 2.9, 3.6, 3.7, 3.6, 3.3 and $2.9 \AA$, respectively (Figure 2). The substituted 
phenyl ring of the selected compounds projected in the hydrophobic pocket displaying the hydrophobic interactions with Phe446 residue whereas thiazolidine2-one ring showed hydrophobic interaction with Met347 residue of PDE4 protein. The selected compounds $(\mathbf{3}, \mathbf{7}, \mathbf{1 0}, \mathbf{1 1}, 13$ and $\mathbf{1 8})$ showed similar binding pattern and best fit in the active site of the PDE4 protein as that of co-crystallized ligand of PDB 3HMV as seen in the overlay of the selected compounds with the PDB Ligand of 3HMV (Figure 3). The docking of the designed molecules in the active site of PDE4 protein thus helped us in predicting that the designed thiazolidine-2one derivatives could act as potential PDE4 inhibitors.
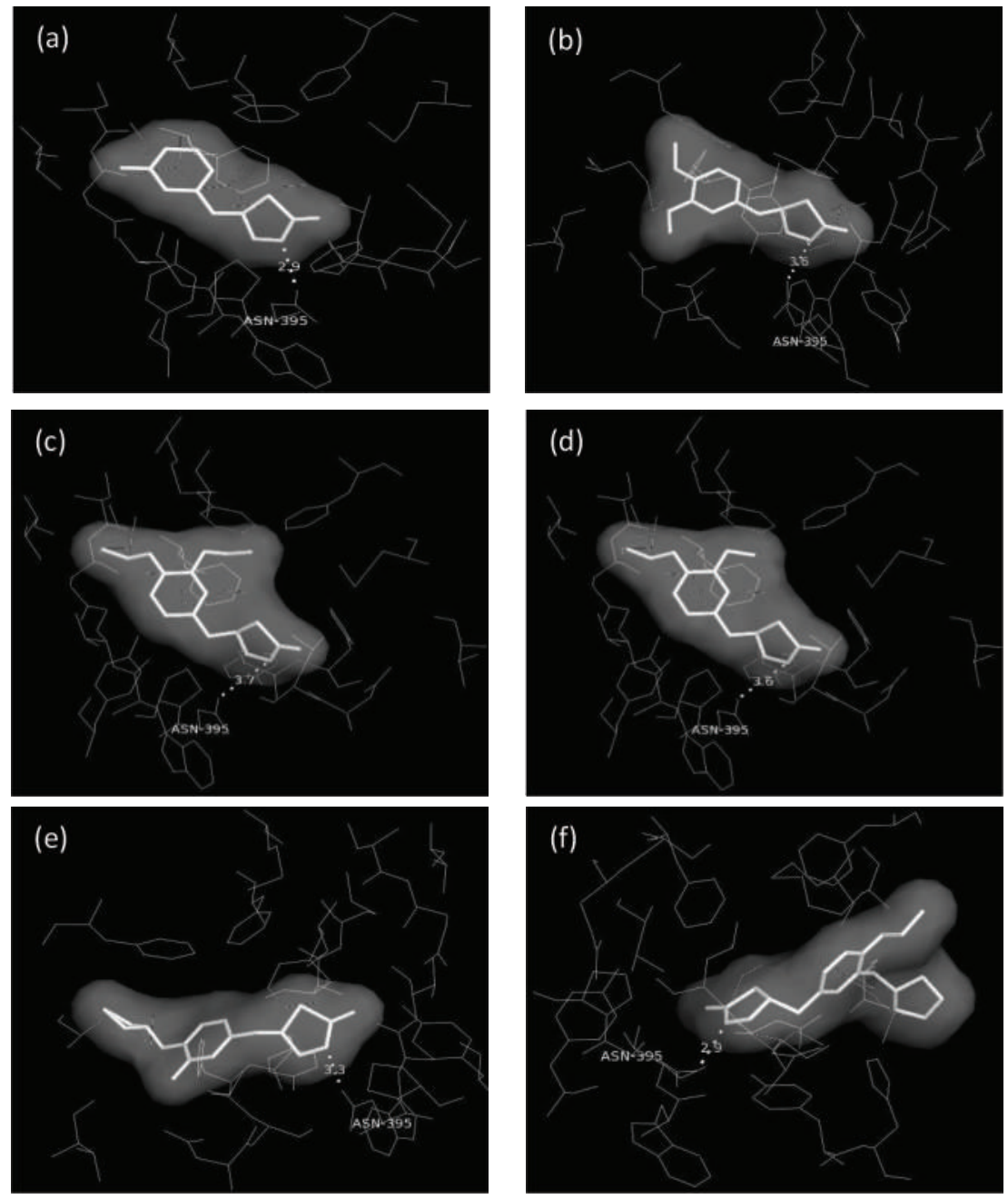

Figure 2: Docked poses showing H-bond interactions for compounds 3 (a), 7 (b), 10 (c), 11 (d), 13 (e)and 18(f) in the active site of PDE4 protein. 
Grewal, A.S. Sharma, N. Singh, S. Arora, S.
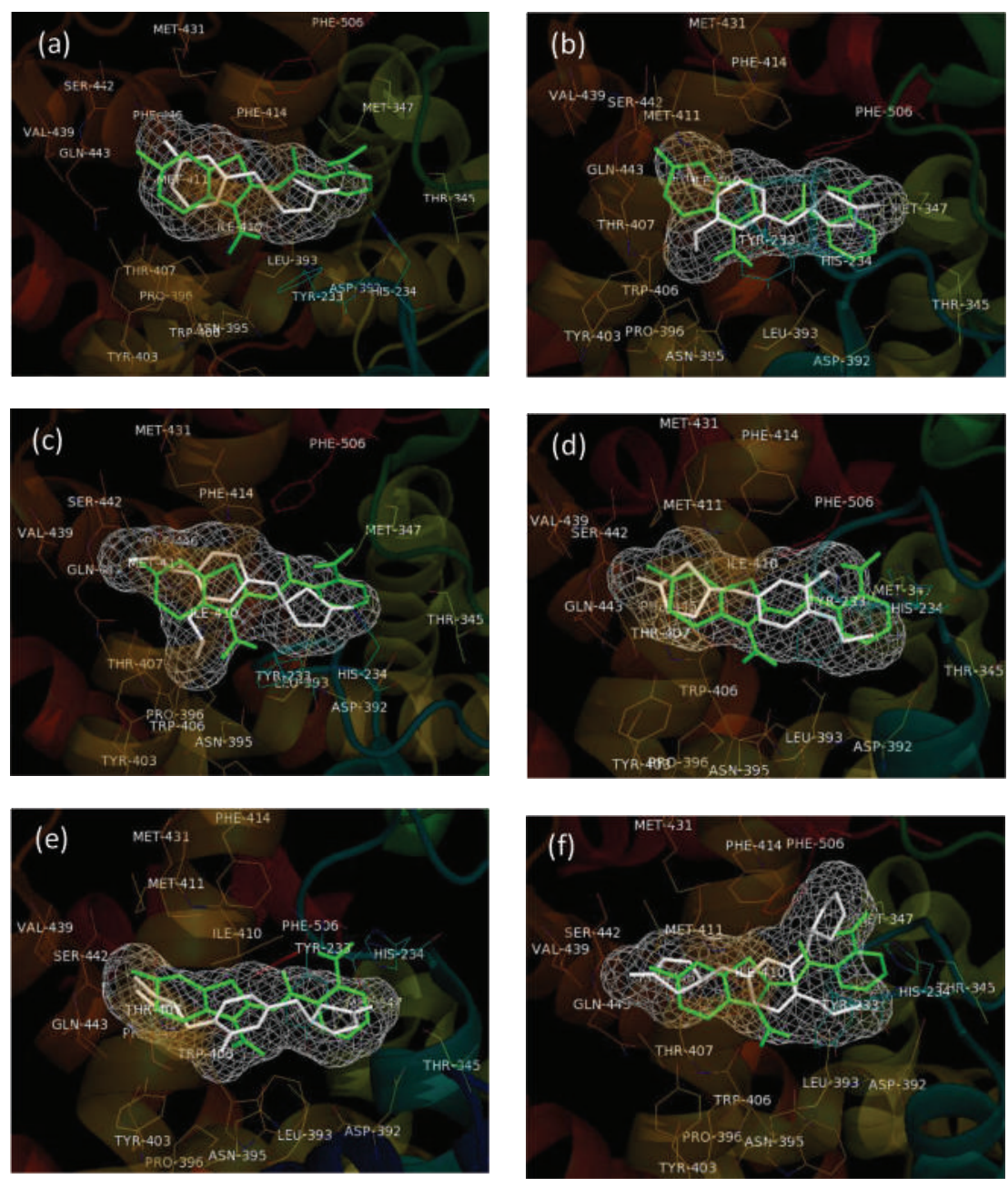

Figure 3: Overlay of the docked pose of compounds 3 (a), 7 (b), 10 (c), 11 (d), 13 (e) and $\mathbf{1 8}$ (f) with that of PDB Ligand of 3HMV in the active site of PDE4 protein.

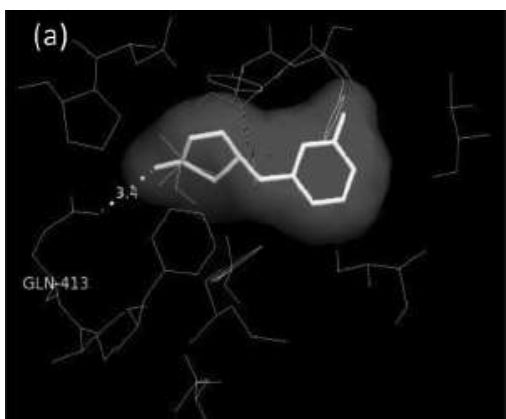



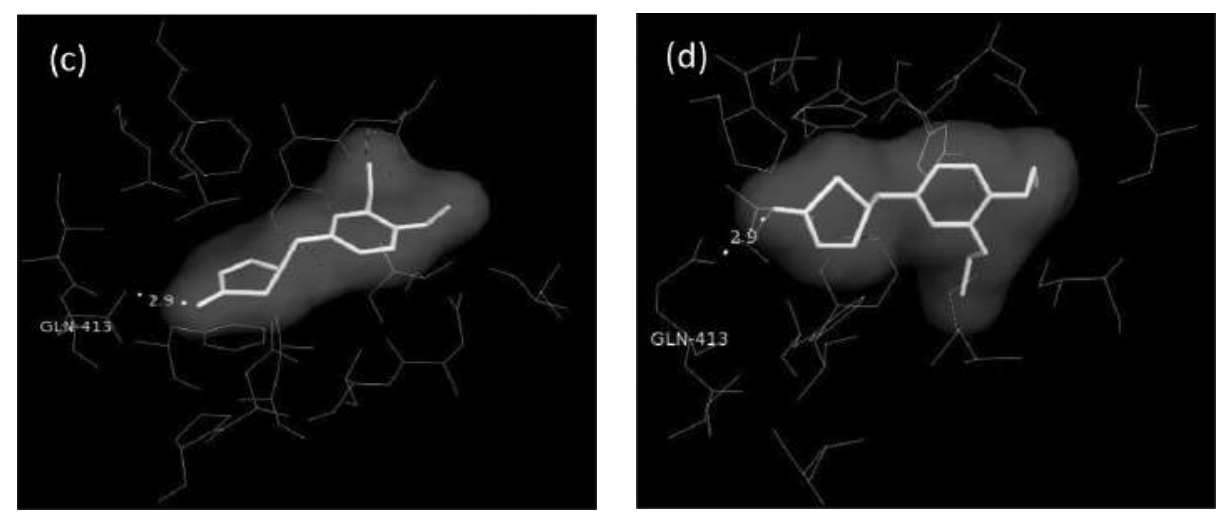

In Silico Designing of Novel

Thiazolidine-2-one Derivatives as Dual

PDE4/7 Inhibitors for Inflammatory Disorders
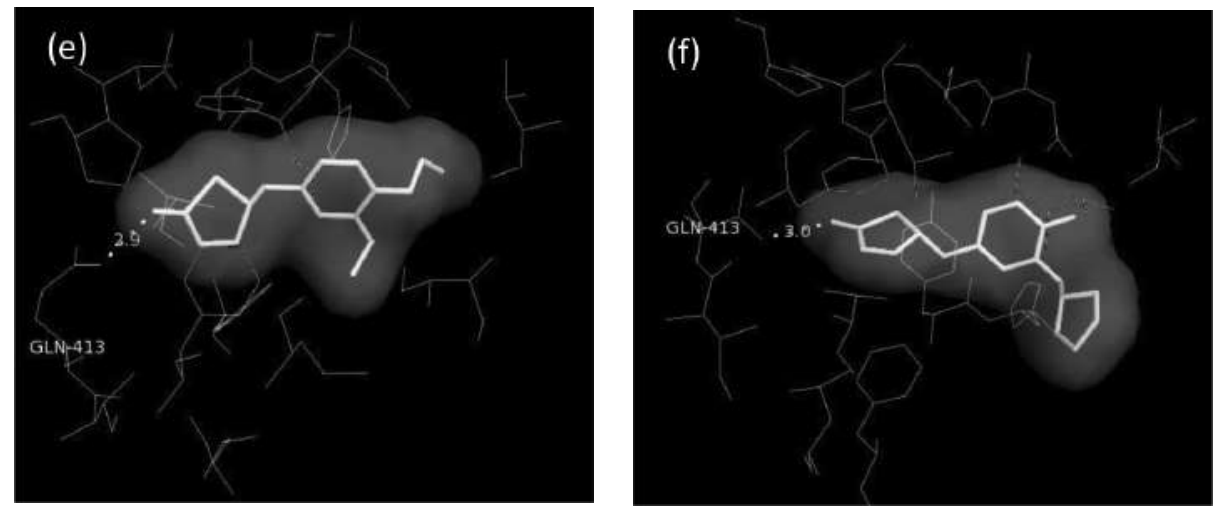

Figure 4: Docked poses showing H-bond interactions for compounds 3 (a), 4 (b), 7 (c), 10 (d), 11 (e)and 14 (f) in the active site of PDE7 protein.
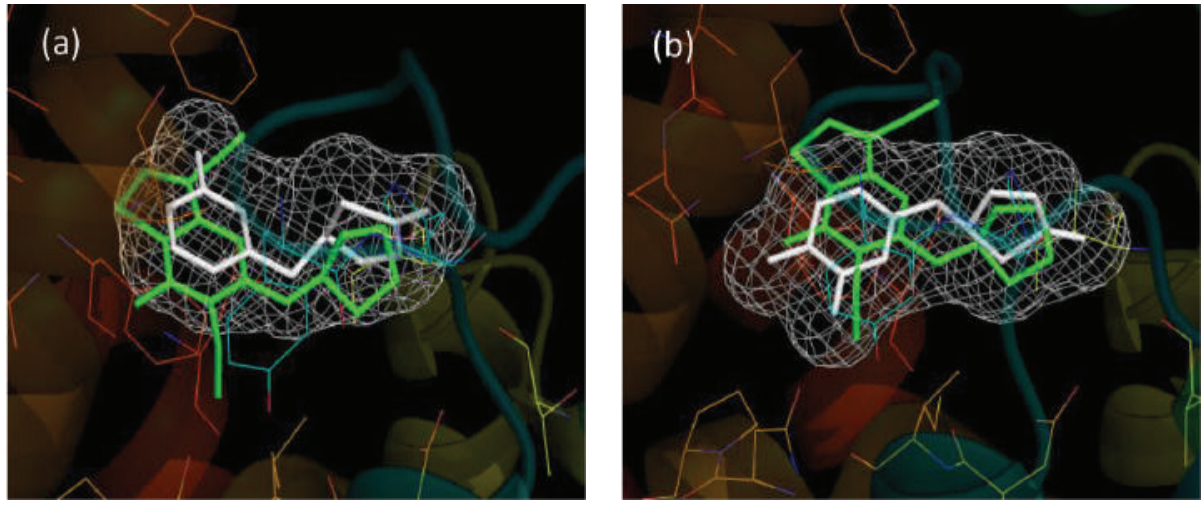
Grewal, A.S. Sharma, N.

Singh, S. Arora, S.
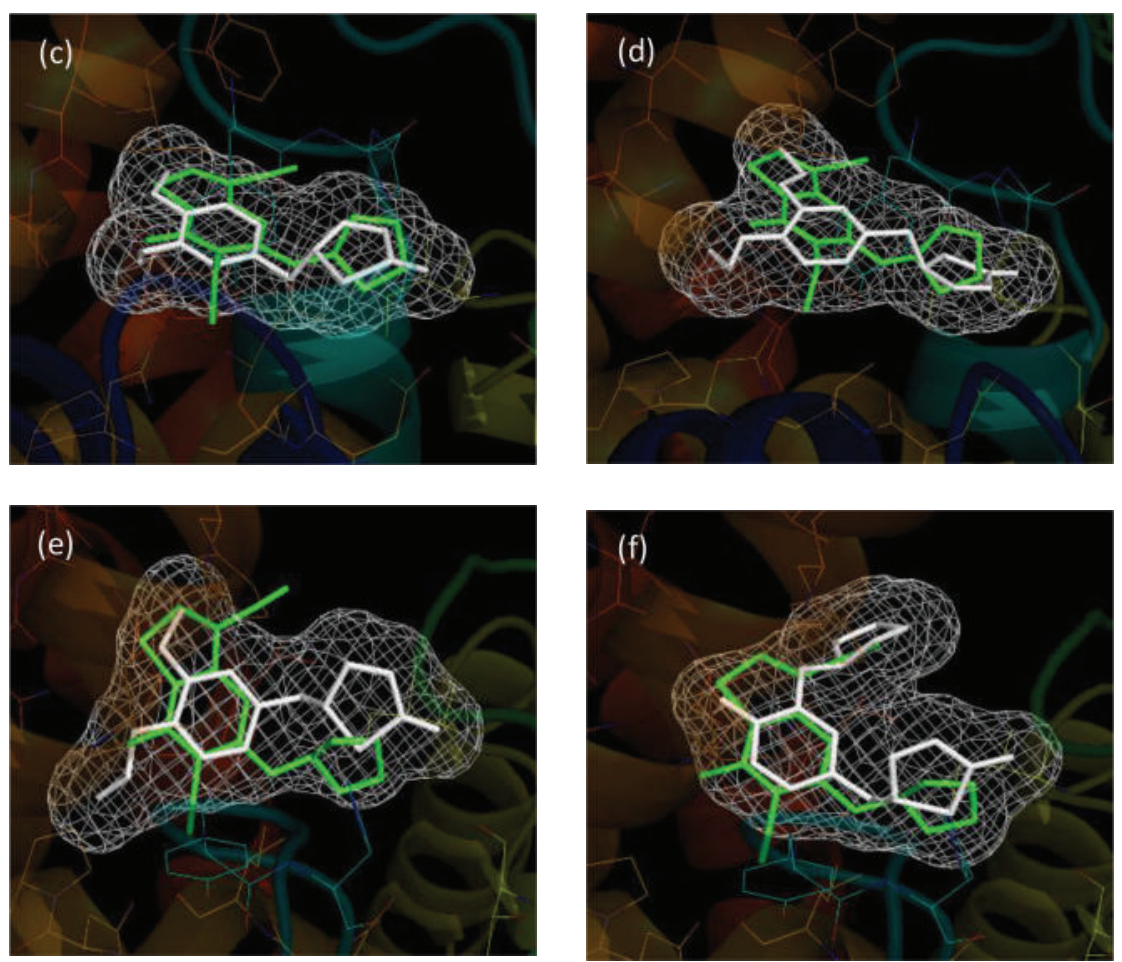

Figure 5: Overlay of the docked pose of compounds 3 (a), 4 (b), 7 (c), 10 (d), 11 (e) and 14 (f) with that of PDB Ligand of 4PM0 in the active site of PDE7 protein.

\section{CONCLUSION}

The present study has been intended to design some newer thiazolidine-2-one derivatives as dual inhibitors of PDE4/7, which can be developed further for their therapeutic benefits in a wide range of inflammatory diseases. Structure based drug design approach was used to design the newer thiazolidine-2-one derivatives by using the X-ray crystallographic data of PDE4 and PDE7 proteins from protein data bank. Based on pharmacophoric requirements for PDE4 and PDE7 binding, thiazolidine-2-one scaffold was selected for the design of novel analogues by suitable substitutions at the five membered heterocyclic ring. Amongst the docked thiazolidine-2-one derivatives, compounds 3, 7, 10 and 11 showed better binding interactions with both PDE4 and PDE7 enzymes indicating that these compounds could act as potential dual inhibitors of PDE4/7. Overall, the newly designed compounds could be used as lead 
molecules for development potent and non-toxic dual inhibitors of PDE4/7 for the management of various inflammatory conditions.

\section{REFERENCES}

[1] Baumer, W., Hoppmann, J., Rundfeldt, C., \& Kietzmann, M. (2007) Highly selective phosphodiesterase 4 inhibitors for the treatment of allergic skin diseases and psoriasis. Inflammation \& Allergy - Drug Targets, 6, 17-26. https://doi.org/10.2174/187152807780077318

[2] Beghè, B., Rabe, F., \& Fabbri, L. M. (2013) Phosphodiesterase-4 inhibitor therapy for lung diseases. American Journal of Respiratory and Critical Care Medicine, 188, 271-278. https://doi.org/10.1164/rccm.201301-0021PP

[3] Burnouf, C., \& Pruniaux, M. P. (2002) Recent advances in PDE4 inhibitors as immune regulators and anti-inflammatory drugs. Current Pharmaceutical Design, 8, 1255-1296. https://doi.org/10.2174/1381612023394665

[4] Caron, S., \& Vazquez, E. (2001) The Synthesis of a Selective PDE4/TNF $\alpha$ Inhibitor. Organic Process Research\&Development, 5, 587-592.

https://doi.org/10.1021/op010223p

[5] Castro, A., Jerez, M. J., Gil, C., \& Martinez, A. (2005) Cyclic nucleotide phosphodiesterases and their role in immunomodulatory responses: advances in the development of specific phosphodiesterase inhibitors. Medicinal Research Reviews, 25(2), 229-244. https://doi.org/10.1002/med.20020

[6] Christensen, I., Miskovicova, H., Porvaznik, I., Joskova, M., Mokra, D., \& Mokry, J. (2012) Selective inhibition of phosphodiesterase 7 (PDE7) by BRL50481 in healthy and ovalbumin-sensitized guinea pigs. ActaMedicaMartiniana, 12, 16-23. https://doi.org/10.2478/v10201-011-0023-7

[7] Conti, M., Richter, W., Mehats, C., Livera, G., Park, J., \& Jin, C. (2003) Cyclic AMP-specific PDE4 phosphodiesterases as critical components of cyclic AMP signaling. Journal of Biological Chemistry, 278, 5493-5496.

https://doi.org/10.1074/jbc.R200029200

[8] Felding, J., Soerensen, M. D., Poulsen, T. D., Larsen, J., Andersson, C., Refer, P., et al. (2014) Discovery and early clinical development of 2-\{6-[2-(3,5-dichloro4-pyridyl)acetyl]-2,3-dimethoxyphenoxy\}-N-propylacetamide (LEO 29102), a soft-drug inhibitor of phosphodiesterase 4 for topical treatment of atopic dermatitis. Journal of Medicinal Chemistry, 57, 5893-5903.

https://doi.org/10.1021/jm500378a

[9] Giembycz, M. A. (2002) Development status of second generation PDE4 inhibitors for asthma and COPD: the story so far. Monaldi Archives for Chest Disease, 57, 48-64.
In Silico Designing

of Novel

Thiazolidine-2-one

Derivatives as Dual

PDE4/7 Inhibitors

for Inflammatory

Disorders

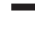


Grewal, A.S.

Sharma, N.

Singh, $\mathrm{S}$.

Arora, S.
[10] Gil,C.,Campillo, N.E.,Perez,D. I., \& Martinez, A. (2008) PDE7 inhibitors as new drugs for neurological and inflammatory disorders. Expert Opinion on Therapeutic Patents, 18, 1127-1139. https://doi.org/10.1517/13543776.18.10.1127

[11] Gil, C., Casta-o, T., Campillo, M. N., Ballester, J. S., González, G. C., \& Hernández, T. (2008a) Compound that is a dual inhibitor of enzymes PDE7 and/or PDE4, pharmaceutical compositions and uses applications. WO Patent 2008113881 A1.

[12] Grewal,A.S.,Lather, V.,Pandita,D.,\& Dalal,R.(2017) Synthesis, docking and antiinflammatory activity of triazole amine derivatives as potential phosphodiesterase-4 inhibitors. Antiinflammatory and Antiallergy Agents in Medicinal Chemistry, 16(1), 58-67. https://doi.org/10.2174/1871523016666170616115752

[13] Grewal, A. S., Kumar, P., Dua, J. S., \& Lather, V. (2017a) Synthesis, docking and anti-inflammatory activity of some newer triazole derivatives as potential PDE7 inhibitors. Journal of Medicinal Chemistry \& Toxicology, 2, 1-7.

[14] Guariento, S., Karawajczyk, A., Bull, J. A., Marchini, G., Bielska, M., Iwanowa, X., et al. (2017) Design and synthesis of 4,5,6,7-tetrahydro-1H-1,2-diazepin7-one derivatives as a new series of phosphodiesterase 4 (PDE4) inhibitors. Bioorganic and Medicinal Chemistry Letters, 27, 24-29. https://doi.org/10.1016/j.bmcl.2016.11.040

[15] Hatzelmann, A., Marx, D., Steinhilber, W., \& Sterk, G. J. (2002) Phthalazinones derivatives useful as PDE4/7 inhibitors. WO Patent 2002085906 A3.

[16] Jankowska, A., Świerczek, A., Chłoń-Rzepa, G., Pawłowski, M., \& Wyska, E. (2017) PDE7-selective and dual inhibitors: advances in chemical and biological research. Current Medicinal Chemistry, 24, 673-700. https://doi.org/10.2174/0929867324666170116125159

[17] Kodimuthali, A., Jabaris, S.S.L., \& Pal, M. (2008) Recent advances on phosphodiesterase 4 inhibitors for the treatment of asthma and chronic obstructive pulmonary disease. Journal of Medicinal Chemistry, 18, 5471-5489. https://doi.org/10.1021/jm800582j

[18] Lakics, V., Karran, E. H., \& Boess, F. G. (2010) Quantitative comparison of phosphodiesterase mrna distribution in human brain and peripheral tissues. Neuropharmacology, 59(6), 367-374. https://doi.org/10.1016/j.neuropharm.2010.05.004

[19] Levy, J., Zhou, D. M., \& Zippin, J. H. (2016) Cyclic adenosine monophosphate signaling in inflammatory skin disease. Journal of Clinical \& Experimental Dermatology Research, 7(1), 1000326.

[20] Man, H.W., Schafer, P., Wong, L.M., Patterson, R.T., Corral, L.G., Raymon, H., et al. (2009) Discovery of (S)-N-[2-[1-(3-ethoxy-4-methoxyphenyl)-2methanesulfonylethyl]-1, 3-dioxo-2, 3-dihydro-1H-isoindol-4-yl] acetamide (apremilast), a potent and orally active phosphodiesterase 4 and tumor necrosis factor-alpha inhibitor. Journal of Medicinal Chemistry, 52, 1522-1524. https://doi.org/10.1021/jm900210d 
[21] Miteva, M. A., Guyon, F., \& Tufféry, P. (2010) Frog2: Efficient 3D conformation ensemble generator for small compounds. Nucleic Acids Research, 38, W622-627. https://doi.org/10.1093/nar/gkq325

[22] Morris, G. M., Huey, R., Lindstrom, W., Sanner, M. F., Belew, R. K., Goodsell, D. S., et al. (2009) Autodock4 and AutoDockTools4: automated docking with selective receptor flexiblity. Journal of Computational Chemistry, 16, 2785-2791. https://doi.org/10.1002/jcc.21256

[23] Nichols, P. J., Demattei, J. A., Barnett B. R., Lefur, N. A., Chuang, T. H., Piscopio, A. D., et al. (2006) Preparation of pyrrolidine-based PDE4 inhibitors via enantioselective conjugate addition of alpha-substituted malonates to aromatic nitroalkenes. Organic Letters, 8(7), 1495-1498. https://doi.org/10.1021/ol060398p

[24] Pelcman,B.,Yee,J.G.,Mackenzie,L.F.,Zhou,Y.,\&Han,K.(2010) Isochromenones useful in the treatment of inflammation. WO Patent 2010076564 A2.

[25] Pitts, W. J., Watson, A. J., \& Dodd, J. H. (2002) Dual inhibitors of PDE 7 and PDE 4. World Intellectual Property Organization 2002088079 A2.

[26] Press, N. J., \& Banner, K. H. (2009) PDE4 inhibitors - a review of the current field. Progress in Medicinal Chemistry, 47, 37-74.

https://doi.org/10.1016/S0079-6468(08)00202-6

[27] Redondo, M., Brea, J., Perez, D.I., Soteras, I., Val, C., Perez, C., et al. (2012) Effect of phosphodiesterase 7 (PDE7) inhibitors in experimental autoimmune encephalomyelitis mice. Discovery of a new chemically diverse family of compounds. Journal of Medicinal Chemistry, 55, 3274-3284.

https://doi.org/10.1021/jm201720d

[28] Rudra, S., Gupta, N., Chandrakant, K. G., Jain, T., Voleti, S. R., Ray, A., et al. (2012) Phosphodiestarase inhibitors. U.S. Patent 20120004201 A1.

[29] Rudra, S., Gupta, N., Baregama, L. K., Agarwal, R., Khairnar, V. V., Ramaiah, M. R., et al. (2013) Pyrazolo (3, 4-B) pyridine derivatives as phosphodiesterase inhibitors. U.S. Patent 8420666 B2.

[30] Sanz, M. J., Cortijo, J., \& Morcillo, E. J. (2005) PDE4 inhibitors as new antiinflammatory drugs: Effects on cell trafficking and cell adhesion molecules expression. Pharmacology \& Therapeutics, 106, 269-297.

https://doi.org/10.1016/j.pharmthera.2004.12.001

[31] Smith,S.J.,Cieslinski,L.B.,Newton,R.,Donnelly,L.E.,Fenwick,P.S.,Nicholson, A.G., et al.(2004) Discovery of BRL 50481 [3-(N,N-dimethylsulfonamido)-4methyl-nitrobenzene], a selective inhibitor of phosphodiesterase 7: in vitro studies in human monocytes, lung macrophages, and CD8+ T-lymphocytes. Molecular Pharmacology, 66, 1679-1689. https://doi.org/10.1124/mol.104.002246

[32] Souness, J. E., Aldous, D., \& Sargent, C. (2000) Immunosuppressive and antiinflammatory effects of cyclic AMP phosphodiesterase (PDE) type 4 inhibitors. Immunopharmacology, 47, 127-162.

https://doi.org/10.1016/S0162-3109(00)00185-5
In Silico Designing of Novel

Thiazolidine-2-one Derivatives as Dual PDE4/7 Inhibitors for Inflammatory Disorders 
Grewal, A.S. Sharma, N. Singh, $\mathrm{S}$. Arora, S.
[33] Tasken, K., \& Aandahl, E. M. (2004) Localized effects of cAMP mediated by distinct routes of protein kinase A. Physiological Reviews, 84, 137-67. https://doi.org/10.1152/physrev.00021.2003

[34] Trott, O., \& Olson, A. J. (2010) AutoDock Vina: improving the speed and accuracy of docking with a new scoring function, efficient optimization and multithreading. Journal of Computational Chemistry, 31, 455-461.

[35] Vávrová,K. (2016) Emerging small-molecule compounds for treatment of atopic dermatitis: a review. Expert Opinion on Therapeutic Patents, 26(1), 21-34. https://doi.org/10.1517/13543776.2016.1101451

[36] Vergne, F., Bernardelli, P., Lorthiois, E., Pham, N., Proust, E., Oliveira, C., et al. (2004) Discovery of thiadiazoles as a novel structural class of potent and selective PDE7 inhibitors. part 1: Design, synthesis and structure-activity relationship studies soulard, P. Bioorganic Medicinal Chemistry Letters, 14, 4607-4613. https://doi.org/10.1016/j.bmcl.2004.07.009

[37] Vergne, F., Bernardelli, P., Lorthiois, E., Pham, N., Proust, E., Oliveira, C., et al. (2004a) Discovery of thiadiazoles as a novel structural class of potent and selective PDE7 Inhibitors. part 2: Metabolism-directed optimization studies towards orally bioavailable derivatives. Bioorganic Medicinal Chemistry Letters, 14, 4615-4621. https://doi.org/10.1016/j.bmcl.2004.07.008 